\title{
Elemental copper recovery from e-wastes mediated with a two-step bioleaching process
}

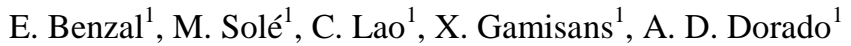 \\ *Corresponding autor: AntonioDavid Dorado (toni.dorado@upc.edu)
}

ORCID numbers of the authors E. Benzal (0000-0002-0045-1341), M. Solé (0000-0002-0854-4649), C. Lao (00000002-7342-7801), X. Gamisans (0000-0003-1856-8692) and A.D. Dorado (0000-0003-0238-5867)

${ }^{1}$ Department of Mining, Industrial and ICT Engineering, UniversitatPolitècnica de Catalunya, Av. Bases de Manresa 61-73, 08242 Manresa, Spain

Keywords: bioleaching, copper, electronic waste, Acidithiobacillus ferrooxidans, two-steps, cementation.

\begin{abstract}
Copper recovery from printed circuit boards (PCB) from waste mobile phones was investigated using a two-step bioleaching process. The method consists of a first step where $\mathrm{Fe}(\mathrm{II})$ ions are biologically oxidised to Fe(III) by Acidithiobacillus ferrooxidans. Later, Fe (III) ions are put in contact with the PCBs for copper solubilisation. At the conditions tested in the present work, the Fe(II) bio-oxidation (first step) was almost completed in $48 \mathrm{~h}$. Two different methods (filtration and sedimentation) for biomass separation before the second step were tested. No significance differences between both separation methods were observed in terms of the overall process efficiency. In both cases, using $7.5 \mathrm{~g} / \mathrm{L}$ of e-waste concentration, copper recovery of $95-100 \%$ were obtained in only 48 hours. In order to test an inexpensive and environmental friendly method to recovery the copper from the leachate solution, cementation of $\mathrm{Cu}$ (II) with metallic iron was performed. The copper powder obtained had purity of $64.8 \%$.
\end{abstract}

\section{Graphical abstract}

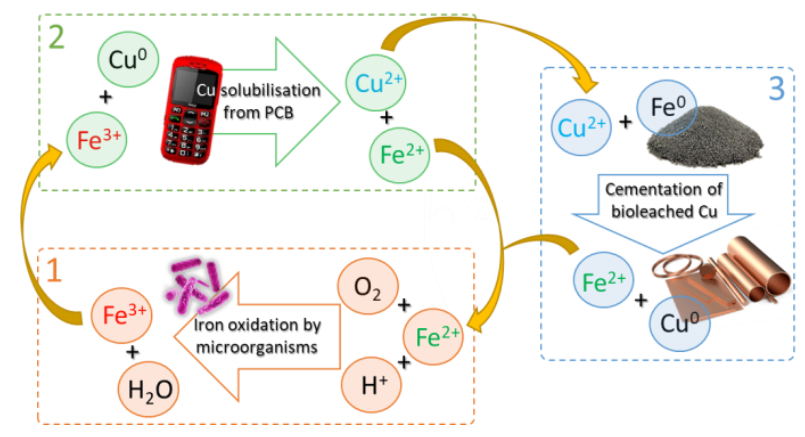

\section{Acknowledgments}

This work has been founded by the project 2016LLAV00034 founded by AGAUR and FEDER funds. Eva Benzal gratefully acknowledges a FPU-2014 predoctoral scholarship from Ministerio de Educación, Cultura y Deporte (Spain) and co-financed by FEDER funds.

\section{Statement of Novelty}

Bioleaching has been evaluated to recover copper from e-waste by means of a novel discontinuous process, which significantly reduced the time reported from several days to only 48 hours. Optimizing 
separately the biooxidation of Fe (II) and the subsequent copper solubilisation, it was possible to recover $100 \%$ of the copper in its metallic state. The reuse of streams between the different steps in a circular loop enables the total metal recovery by means of a more sustainable and economic alternative with high industrial potential.

\section{INTRODUCTION}

The increasing generation of electronic wastes is a worldwide problem. In particular, 44.7 million tons of e-waste were produced in the world in 2016 and it is estimated to be more than 50 million tons by 2021 [1]. One of the main concerns with this type of e-waste is that they contain toxic chemicals (arsenic, lead, mercury and poly-brominated flame retardants among others). On the other hand, e-waste also have a significant amount of valuable metals such as copper, silver or gold, which could be recovered to be reused [2]. Within the e-waste, mobile phones are one of the most important target [3]. It has been reported that more than 781 million mobile phones were generated in 2015, increasing it to 877 million units by 2020 [4]. In addition, it is possible to obtain $130 \mathrm{~kg}$ of Cu, $3.5 \mathrm{~kg}$ of Ag and $340 \mathrm{~g}$ of Au from one tone of mobile phones [5].Taking these into account, mobile phones can be considered as an important source for metals extraction.

Currently, chemical methods such as hydrometallurgical [6] and pyrometallurgical processes, in particular Rönnskar, Noranda and Umicore processes [7] are employed to recover metals from waste. Recently, bioleaching has been proposed as an alternative to conventional physical-chemical processes, showing important advantages such as low cost, high efficiency and environmental friendliness [8]. Bioleaching process has been studied for many years in the mining field [9-11], especially when low-grade ores have to be treated, due to the low cost of bioleaching process [12]. This technique, which has proven to be effective in this field, has been extended for the metal extraction from other possible metals sources [13, 14].

Bioleaching is based on the release of metals from metal concentrates, as e-waste or ores, using microorganism's activity. Regarding to the microorganisms, chemoautotrophic bacteria are one of the most useful to bioleach $[15,16]$. They are aerobic and grow in very acidic conditions ( $\mathrm{pH}, 1.5-3.0)$ [17]. The microorganism has an indirect role in copper bioleaching. In fact, copper is oxidized by Fe(III) ions which in turn, are reduced to $\mathrm{Fe}(\mathrm{II})$. The task of the microorganism is the oxidation of $\mathrm{Fe}$ (II) to $\mathrm{Fe}(\mathrm{III})$, regenerating the agent responsible of copper bioleaching [8]. According to these authors, an iron cycle occurs during the leaching process of copper following Eq. (1) and (2).

$$
\begin{aligned}
& \mathrm{Cu}^{0}+2 \mathrm{Fe}^{3+} \rightarrow \mathrm{Cu}^{2+}+2 \mathrm{Fe}^{2+} \\
& 4 \mathrm{Fe}^{2+}+4 \mathrm{H}^{+}+\mathrm{O}_{2} \stackrel{\text { Biologicalactivity }}{\longrightarrow} 4 \mathrm{Fe}^{3+}+2 \mathrm{H}_{2} \mathrm{O}
\end{aligned}
$$

Most studies dealing with bioleaching have been performed in one step using different kind of microorganisms [18-20]. In one-step bioleaching, iron oxidation and bio-mediated leaching reagent recovery process itself are developed in the same reactor. However, it has been reported that the bacteria could be affected by toxic compounds which could be found in the e-waste treated [21-23]. For this reason, a bioleaching process carried out in two steps could be very suitable in order to avoid toxicity issues and thus, improve the extraction of metals during the bioleaching $[24,25]$. The goal of the first step is to obtain the Fe (III) ions required in the second step to extract the copper from the PCB waste (Eq 1). It's important to consider that iron may be found in different speciation forms dependent on the $\mathrm{pH}$ media [26]. So the speciation form of iron is crucial for its solubility and bioavailability by microorganisms [27]. In the two steps processes, the microorganisms growth is performed in the absence of electronic scrap and then, the scrap is added to the culture to carry out the leaching process [28-30]. In general, the two steps method allows to leach larger amount of e-waste. However, most of the two steps bioleaching experiments reported in the literature took from 3 to 15days to obtain acceptable copper recoveries $[24,28-30]$. These are quite long time for an economically viable application, especially to scale-up the technology as an alternative to conventional processes.

Once copper has been bioleached from the electronic waste, different methods can be applied in order to transform copper ions in aqueous solutions into its metallic form. [31-33]. One of the simplest and lowest 
cost method is cementation, which consists of precipitating a metal ion from a liquid solution by a more reducing metal [34]. This method has been extensively used in the hydrometallurgy field. However this technique has seldom been used in the bioleaching area [35, 36]. According to Dib and Makhloufi [37], cementation of copper is usually performed by iron which reacts with copper ions followigEq. (3).

$$
\mathrm{Cu}^{2+}+\mathrm{Fe}^{0} \rightarrow \mathrm{Cu}^{0}+\mathrm{Fe}^{2+}
$$

The aim of the present work was to optimize the copper bioleaching from e-waste through a two-step process in order to shorten process execution times. The optimal conditions for the biological oxidation of iron by the activity of Acidithiobacillus ferrooxidans, in the first step were stablished. Two different methods to separate the biomass after the first-step were studied in order to reuse the biomass. In the second step, copper dissolution kinetic was monitored. Finally, the cementation process was tested as the simplest way to obtain copper in its metallic state from the bioleaching solution and the overall process efficiency was analyzed in terms of metal recovery and time.

\section{MATERIALS AND METHODS}

\subsection{Electronic scrap}

The printed circuit boards (PCB) used in this study came from end-of-life mobile phones model NOKIA 3510. All the mobile phones used corresponded to the same model in order to homogenize the initial sample. The main electronic components such as battery, resistors, capacitors and chips, among others, were separated manually. Then, the PCBs were crushed and sieved and the particles between 0.2 and $1.00 \mathrm{~mm}$ of diameter were collected for experimental purposes.

\subsection{Microorganisms and mineral medium}

The bacterial strain Acidithiobacillus ferrooxidans (ATCC23270) was used in the biological step. It was kindly provided by the Department of Chemical Engineering from the University of País Vasco (Spain). The mineral medium used in the experiments contained (in g.. $\left.{ }^{-1}\right)$ : $\left(\mathrm{NH}_{4}\right)_{2} \mathrm{SO}_{4} 3.00 ; \mathrm{K}_{2} \mathrm{HPO}_{4} 0.50 ; \mathrm{MgSO}_{4}$ . $7 \mathrm{H}_{2} \mathrm{O} 0.50 ; \mathrm{KCl} 0.10 ; \mathrm{Ca}\left(\mathrm{NO}_{3}\right)_{2} \cdot 4 \mathrm{H}_{2} \mathrm{O} 0.014$ and $\mathrm{FeSO}_{4} \cdot 7 \mathrm{H}_{2} \mathrm{O} 30$. The medium was prepared dissolving all the components (except $\mathrm{FeSO}_{4} \cdot 7 \mathrm{H}_{2} \mathrm{O}$ ) in $900 \mathrm{~mL}$ of distillate water. The $\mathrm{pH}$ was adjusted with $\mathrm{H}_{2} \mathrm{SO}_{4} 10 \mathrm{~N}$ to $\mathrm{pH}$ 1.7. Then, $30 \mathrm{~g}$ of $\mathrm{FeSO}_{4} \cdot 7 \mathrm{H}_{2} \mathrm{O}$ were dissolved in $100 \mathrm{~mL}$ of distillate water and the $\mathrm{pH}$ was also adjusted with $\mathrm{H}_{2} \mathrm{SO}_{4} 10 \mathrm{~N}$ to 1.7. After that, both solutions were mixed and the $\mathrm{pH}$ was readjusted again to 1.7 if it was necessary.

\subsection{Bioleaching experiments}

Bioleaching experiments were performed in two steps. The first one consists of the biological oxidation of $\mathrm{Fe}(\mathrm{II})$. Two series of experiments were carried out at initial $\mathrm{pH} 1.7$ in which the $\mathrm{pH}$ was controlled at this value during the experiment whereas in the other one, the $\mathrm{pH}$ was not controlled. Each flask was initially inoculated with $30 \%$ of fresh culture using the medium described in the above section, using a total volume of $350 \mathrm{~mL}$ in $500 \mathrm{~mL}$ baffled Erlenmeyer flask. Furthermore, an abiotic control was also performed under the same conditions. The flasks were maintained at $30^{\circ} \mathrm{C}$ in an orbital shaker incubator at $130 \mathrm{rpm}$ and the $\mathrm{pH}$ and the oxidation-reduction potential periodically. When all the $\mathrm{Fe}$ (II) had been oxidized to Fe(III) by the microorganisms, it was considered that the first step was finished. Afterwards, solution containing this biogenerated $\mathrm{Fe}(\mathrm{III})$ was pot in contact with the e-waste. This second step was performed with $350 \mathrm{~mL}$ of $\mathrm{Fe}$ (III) biogenerated solution and 2,625 g of waste in $500 \mathrm{~mL}$ baffled Erlenmeyer flasks in an incubator at $30{ }^{\circ} \mathrm{C}$ and $130 \mathrm{rpm}$ during 2 days. Samples taken every 2-3 hours during the two steps were filtered and diluted before being analysed to determine the iron and/or copper concentration.

Two different methods (filtration and sedimentation) were tested to separate the biomass from Fe(III) solution before step 2 in order to reuse the biomass in step 1 and also to avoid its inhibition by the possible toxic metals bioleached during the step 2 . For the filtration, a $0.22 \mu \mathrm{m}$ membrane filter of 
cellulose acetate was used whereas for the sedimentation, the solution was transferred to a beaker and after 2 hours of settling, the solution is separated from the biomass by decanting.

\subsection{Cementation experiments}

After bioleaching, $\mathrm{Cu}(\mathrm{II})$ present in the bioleachated solution was reduced to metallic copper by cementation. $100 \mathrm{~mL}$ of the bioleachate, previously filtered by $0.45 \mu \mathrm{m}$ membrane, were placed in a 250 $\mathrm{mL}$ Erlenmeyer flask with $4 \mathrm{~g} / \mathrm{L}$ of iron filings (7439-89-6, Fischer Scientific). The process was performed in an incubator at 130 rpmand $25^{\circ} \mathrm{C}$. Samples of the solution were taken every hour and they were filtered and diluted before being analysed to determine their $\mathrm{Cu}(\mathrm{II})$ content. When all the copper had been cemented, the solution was decanted and the solid copper obtained was dried and analysed for its composition as described in section 2.5.

\subsection{Analytical methods}

In order to determine the metal content in the PCB and in the copper powder obtained by cementation, $0.15 \mathrm{~g}$ of each sample were digested with $10 \mathrm{~mL}$ of $\mathrm{HNO}_{3}: \mathrm{HCl}(3: 1)$ at $150{ }^{\circ} \mathrm{C}$ for 15 minutes in a microwave apparatus (Microwave System, Millestone, Italy). $\mathrm{Cu}, \mathrm{Pb}, \mathrm{Ni}$ and $\mathrm{Fe}$ were determined by atomic absorption spectrometry (Solar S2, Thermo Scientific, United States) in triplicate and the coefficient of variation were among 2,9 and 4,4\%. The other metal (Ag, Au, Mn, Pd, In, Sn and Co) were determined by ICP/MS (7500CX, Agilent Technologies,United States).

Total iron and copper ions concentration in the bioleachates were analysed by an atomic absorption spectroscopy (Solar S2, Thermo Scientific, United States). Fe(II) determination was carried out by the 1,10-phenanthroline method [38] with an UV/VIS spectrophotometer (Lambda 25, PerkinElmer, United States). The same spectrophotometer was used for optical density measurements, using the method described by Barron et Luecking (1990) [39]. Oxidation-reduction potential and $\mathrm{pH}$ were measured with a multimeter (MultiLine Multi3620 IDS, WTW, Germany). Solid copper powder obtained by cementation was analysed by SEM microscopy (TS-1000, Hitachi, United States), and it was characterized by Energy Disperse Spectroscopy (EDS), connected to SEM microscope (XFlash Min SVE, Hitachi, United States).

\section{RESULTS AND DISCUSSION}

\subsection{PCB metal composition}

The PCBs metal composition used in this study is showed in Table 1 . $\mathrm{Cu}$ was found to be the major component and the total metal content per kilogram was $452245 \mathrm{mg}$. Therefore, PCB of mobile phones could be a good source of this metal to take advantage of them in comparison to the metals found in some ores, which have a copper concentration between 0.5 and $3.0 \%$ generally [40-42].

\subsection{Optimization of biological Fe(II) oxidation}

Figure 1 shows the concentration of $\mathrm{Fe}(\mathrm{II})$ and $\mathrm{Fe}(\mathrm{III})$ ions over time. As can be seen, practically all the $\mathrm{Fe}$ (II) ions was oxidised to $\mathrm{Fe}$ (III) in 45 hours in presence of microorganisms whereas in the abiotic test the $\mathrm{Fe}(\mathrm{II})$ remained almost unchanged. Some authors have observed that the oxidation of $\mathrm{Fe}(\mathrm{II})$ into $\mathrm{Fe}(\mathrm{III})$ is not only consequence of microorganisms' activity but also chemical oxidation has an important contribution to the oxidation of this metal [43, 44]. However, in the present work, under the conditions applied, in 45 hours no chemical oxidation was produced. It means that the chemical oxidation of iron is too slow to be significant in this period of time. In the case of the flasks with the adjusted $\mathrm{pH}, \mathrm{H}_{2} \mathrm{SO}_{4} 10 \mathrm{~N}$ was added by dropwise at different times to maintain the $\mathrm{pH}$ between 1.7 and 1.8 , following the methodology described in the section 2.3. As it can be observed, in both biotic experiments, with and without controlled $\mathrm{pH}$ a $100 \%$ oxidation of $\mathrm{Fe}(\mathrm{II})$ was achieved. In the biotic flask subjected to $\mathrm{pH}$ control, after 3 hours, $\mathrm{Fe}$ (II) concentration constantly decreased becoming zero after $45 \mathrm{~h}$ whereas $\mathrm{Fe}$ (III) concentration increased achieving a concentration near $6000 \mathrm{mg} / \mathrm{L}$ in 45 hours. This indicates that under the activity of the microorganisms the whole $\mathrm{Fe}(\mathrm{II})$ was transformed into $\mathrm{Fe}(\mathrm{III})$. It is noticed that the 
microorganisms oxidized $0.125 \mathrm{~g} / \mathrm{L}$ of $\mathrm{Fe}$ (II) per hour, which is a similar oxidation rate that are reported by Choi et al $(0,15-0,13 \mathrm{~g} / \mathrm{L}$ per hour) [17] and Xiang et al. $(0,125 \mathrm{~g} / \mathrm{L}$ per hour ) [45], despite $9 \mathrm{~g} / \mathrm{L}$ of $\mathrm{Fe}$ (II) was used in their mineral media instead of the $6 \mathrm{~g} / \mathrm{L}$ was used herein. Initial Fe (II) concentration, culture medium and hydraulic residential time influences notably the oxidation rate in continuous production of $\mathrm{Fe}$ (III) [46]. Nonetheless, it is important to highlight that in the experiment carried out with controlled $\mathrm{pH}$ the total iron concentration remains constant $(6000 \mathrm{mg} / \mathrm{L})$. However, when there is no acid addition during the biological oxidation, after 30 hours the total iron concentration decreased from 6000 $\mathrm{mg} / \mathrm{L}$ to under $4000 \mathrm{mg} / \mathrm{L}$. This loss of iron may be attributed to the precipitation of the iron ions as $\mathrm{Fe}(\mathrm{OH})_{3}$ due to the alkalinisation of the media $(\mathrm{pH}>4)$ and the formation of jarosite [47].

\subsection{Cu extraction from PCBs with bio-generated Fe(III) after biomass separation}

To avoid the presence of the biomass during the second step, two methods, sedimentation and filtration, were tested in the present work. Filtration was set through a $0.22 \mu \mathrm{m}$ membrane filter and clarification of the media by decantation which was monitoring by determining the optical density (OD) at $500 \mathrm{~nm}$ [36] along time (Fig. 2). Results for decantation showed a sharp drop of OD in two hours. After this time, the optical density had been reduced from 1.00 to 0.17 and remained practically unchanged until 24 hours. Therefore, for practical considerations, the supernatant after two sedimentation hours was taken for leaching tests, although the biomass has not been completely removed from the solution. Figure 3 shows the $\mathrm{Fe}(\mathrm{II})$ and $\mathrm{Fe}$ (III) concentrations and copper recovery along time after filtration. Figure 4 shows the copper recovery and the concentrations of Fe(II) and Fe(III) ions during the leaching stage with the solution obtained after decanting.

Regarding filtration, greatly fast extraction of copper was observed at first and then a much slower phase. After 6 hours, $60 \%$ of the copper present in the PCB was removed and put into solution. This phenomenon could be attributed during the first hours, when $\mathrm{Fe}(\mathrm{III})$ is not limiting, to a quickly extraction from the most readily available sites on the waste particles instead of those internal parts with difficult accessibility. During the first 6 hours, Fe(III) decreased from 4000 to $400 \mathrm{mg} / \mathrm{L}$. Then, it decreased slowly until 24 hours when practically all the $\mathrm{Fe}(\mathrm{III})$ was reduced to $\mathrm{Fe}(\mathrm{II})$. From this moment, both $\mathrm{Fe}(\mathrm{II})$ and $\mathrm{Fe}$ (III) concentrations remained constant during the rest of the experiment which would mean that copper concentration should be also constant (see Eq. 1). Nevertheless, from 24 hours to the end of the experiment, copper still increased despite of the fact that the Fe (III) has run out after 24 hours in the leaching solution. This can be attributed to copper oxidation by the dissolved oxygen in the acidic medium [48]. These authors affirmed that the continuous stirring of the leaching solution causes the oxygen gas incorporation and its dissolution in the liquid, which is able to oxidize metallic copper (Eq. 4). This is probably why the removal in 6 hours was quite superior (53\%) to those obtained the next 42 hours of contact (41\%). Bas et al. [19] also described the copper solubilisation by the action of the oxygen, working at $\mathrm{pH} 1.7$ and $35^{\circ} \mathrm{C}$ during $90 \mathrm{~h}$, although the effect was observed since the beginning of the experiment. Taking into account the conditions of the experiments in the present study (pH 1.75 and $30^{\circ} \mathrm{C}$ ), it is assumed that dissolved oxygen is also the responsible of the copper solubilization. Both reactions occur simultaneously but at different kinetics. Only when Fe(III) is completely depleted the unique effect of copper oxidation by the dissolved oxygen in the acidic medium is clearly appreciable for long time exposure."

$$
2 \mathrm{Cu}^{0}+4 \mathrm{H}^{+}+\mathrm{O}_{2} \rightarrow 2 \mathrm{Cu}^{2+}+2 \mathrm{H}_{2} \mathrm{O}
$$

Figure 4 shows the copper recovery after decanting. As can be seen, the velocity of copper extraction was very similar to the velocity obtained after the total separation of biomass by filtration (see Fig. 3). However, regarding $\mathrm{Fe}(\mathrm{III})$ concentration, in this case decreased near $60 \%$ during the first 6 hours but, after this period, the $\mathrm{Fe}(\mathrm{III})$ concentration increased whereas the $\mathrm{Fe}(\mathrm{II})$ concentration decreased. This behaviour can be attributed to the presence of microorganisms, since, although almost all the microorganisms have been removed by settling and decantation, the separation was not about $100 \%$ so the remaining microorganisms could oxidize the $\mathrm{Fe}(\mathrm{II})$ from the solution.

After the biological production of $\mathrm{Fe}(\mathrm{III})$, this ion has to be kept in contact with the PCB in order to extract the copper from the electronic scrap. Generally, this contact is done by the direct addition of the ewaste in the solution where the microorganisms have been grown when the color of the medium turned 
red which indicate that all the $\mathrm{Fe}$ (II) has been oxidized [29] or at different times during the growth stage $[30,45]$.

Some of these studies present experiments using bio-generated Fe(III) filtered solutions to remove the biomass and it is compared to the copper extraction from the waste using the filtered and the non-filtered solutions. However, the results are contradictory. Yang et al. [29] affirmed that the copper extraction after $72 \mathrm{~h}$ is nearly $100 \%$ in the presence of biomass whereas if it is removed from the solution, the copper extraction in $72 \mathrm{~h}$ is only $10 \%$. On the other hand, Shah et al. [30] affirmed that after 6 days of contact between the bio-generated $\mathrm{Fe}$ (III) solution and the waste, the presence or the absence of the biomass in the solution involves just a difference of $10 \%$ of leached copper $(89 \%$ extraction in the filtered solution and $99 \%$ in the non-filtered solution). The main difference between these studies is the contact time since the first one took $72 \mathrm{~h}$ whereas the second one took 6 days. Even so, the influence of biomass in the copper extraction when $\mathrm{Fe}$ (III) has been obtained by biological oxidation is not clear in the literature. In the light of results obtained herein, there is no significant differences in copper recovery independently on the method used to separate the biomass. Moreover, the extraction is nearly $100 \%$ of the copper contained in the e-waste in $48 \mathrm{~h}$ in both cases. Therefore, the experimental time described in other works [28, 30, 45] has been clearly reduced due to an accurate control of process conditions. Moreover, taking into account the results obtained in the present work, although sedimentation does not lead to a complete remove of biomass, it is simpler and cheaper than filtration, especially when the bioleaching process has to be adapted to an industrial scale.

\subsection{Cementation of bioleached copper}

The suitability of the cementation process to recover metallic copper by addition of metallic iron, (Eq. 3), was investigated. This reaction is spontaneous because copper is higher on the galvanic series than iron. In this study the leaching solution obtained in the previous section using the sedimentation method was put in contact with metallic iron to obtain a metallic copper.

Considering that the $\mathrm{Cu}(\mathrm{II})$ concentration obtained after bioleaching was $3000 \mathrm{mg} / \mathrm{L}, 4 \mathrm{~g} / \mathrm{L}$ of metallic iron filings were used since this is $150 \%$ the concentration needed to react with the copper according to the stoichiometry of the cementation reaction (Eq. 3). A greater amount of iron than what is stoichiometrically needed was added due to it improves the efficiency of the process [37]. The experiment was done under orbital agitation at $130 \mathrm{rpm}$ and at $25^{\circ} \mathrm{C}$.

Figure 5 shows the concentration of $\mathrm{Cu}$ (II), $\mathrm{Fe}$ (II) and $\mathrm{Fe}$ (III) in the solution along time over the cementation process. As it can be seen, the concentration of copper decreased from $3000 \mathrm{mg} / \mathrm{L}$ to $0 \mathrm{mg} / \mathrm{L}$ in only 2 hours. Anastassakis et al.(2015) spend more than 8 hours to remove all the solubilized copper from the solution by cementation [49]. As a consequence of the redox reaction, the scrap iron used $\left(\mathrm{Fe}^{\mathrm{o}}\right)$ was oxidized into $\mathrm{Fe}$ (II) ions. For this reason, the $\mathrm{Fe}(\mathrm{II})$ concentration was found to be $7000 \mathrm{mg} / \mathrm{L}$ after the cementation process, since $4000 \mathrm{mg} / \mathrm{L}$ were initially in solution and came from the bioleaching process whereas the other $3000 \mathrm{mg} / \mathrm{L}$ were obtained by oxidation of the metallic iron filings. It is noticed that $\mathrm{Fe}$ (II) was not virtually oxidized at the conditions tested, so the concentration of Fe(III) remained constant at concentrations below $1000 \mathrm{mg} / \mathrm{L}$ during the whole experiment.

The solid copper was recovered as powder on the surface of iron filings. Because of the stirring, mechanical friction between the copper powder and the metallic iron copper breaks off from the layer deposited on the iron metal. This fact made easier the separation of the copper by filtration or decanting. During the cementation, copper was obtained as a fine brown powder (Fig. 6). This powder was analysed following the procedures described in section 2.5. and the results showed the following content (in $\mathrm{mg} / \mathrm{kg}$ ):Cu (648000), Ni(57), Fe(208879), Ag(11), Au(57), Al (33), Pd(5), In(5), Sn(59), Pb(150), Co (11) and Mn (1414). This cemented powder had a content of copper close to 70\%. The most important impurities in the powder were iron $(21 \%)$ and manganese $(0.14 \%)$. The concentration of the other metals was negligible.

Figure 7 shows the morphology of the powder obtained by SEM microscope. The images demonstrate 
composition of the powder obtained was determined by its analysis conducted with an energy-dispersive X-ray spectroscopy (EDS) (Fig. 8). Basically, EDS spectrum showed the presence of copper and iron. It is possible that iron was not separated from the copper completely, as stated previously, so some metallic iron fillings that have not react with soluble copper during the cementation remained mixed with the powder. In spite of this, no more metals were found during the analysis which means that the purity obtained could be improved conducting a refining step of the copper powder after the cementation process.

After cementation, $2.96 \mathrm{~g}$ of metallic copper were obtained from a litre of bioleaching solution. This metallic copper had a purity close to $70 \%$, which means that other metals or impurities have been also cemented during the process as it is explained above. This can affect the final use of the copper obtained [50]. Nevertheless, cementation is a very economical and simple process to obtain metallic copper. Even though, if more purity is needed, there are methods to do after the cementation such as solvent-extraction or electrowinning in order to obtain high purity copper [31,51]. Despite of that, the cementation has also the advantage that the solution obtained after the process contains an important amount of $\mathrm{Fe}(\mathrm{II})$ in solution which could be reused as electron donor in the leaching agent production step [45]. However, this solution might also contain other metals that could be toxic for the microorganisms [52, 53], so that, the toxicity on the biological activity should be analysed.

\section{CONCLUSIONS}

Under the conditions applied in this study, initial concentration of Fe(II) $6 \mathrm{~g} / \mathrm{L}$ and $\mathrm{pH}$ control between $1,7-1,8, \mathrm{Fe}$ (II) is completely oxidized by microorganisms into $\mathrm{Fe}(\mathrm{III})$ in $45 \mathrm{~h}$. The extraction of copper from the PCBs, after removing the biomass, is not influenced by the method applied to separate the biomass. Sedimentation and filtration gave very similar percentages of copper extraction (close to $100 \%$ in 48h). Filtration allowed to remove the whole biomass, present whereas after sedimentation some biomass remained in suspension. This is possibly why the Fe(III) concentration slightly increased along the extraction process after sedimentation. To the best of our knowledge, this is the first time that sedimentation and filtration techniques (between the oxidation step and the leaching step in two steps bioleaching) have been compared for copper recovery from PCBs. Since both techniques gave good results, the use of filtration or sedimentation depends on the final aim. In this sense, filtration removes all the biomass but its maintenance is more complicated and expensive than the maintenance of a settler, especially when the process is carried out at industrial scale.

Finally, it was possible to conclude that the cementation procedure allowed to obtain elemental copper from the extract in a simply, low cost and environmental friendly way with a relative interesting purity.

In conclusion, the overall process of copper extraction has been optimized in this work by significantly reducing the experimental time without losing efficiency and allowing the recirculation of the biomass before being affected by the possible toxic effect of the leached metals from PCBs. 


\section{REFERENCES}

1. Hsu, E., Barmak, K., West, A.C., Park, A.H.A.: Advancements in the treatment and processing of electronic waste with sustainability: A review of metal extraction and recovery technologies. Green Chem. 21, 919-936 (2019)

2. Fornalczyk, A., Willner, J., Francuz, K., Cebulski, J.: E-waste as a source of valuable metals. Arch. Mater. Sci. Eng. 63, 87-92 (2013)

3. Arshadi, M., Mousavi, S.M.: Multi-objective optimization of heavy metals bioleaching from discarded mobile phone PCBs: Simultaneous $\mathrm{Cu}$ and $\mathrm{Ni}$ recovery using Acidithiobacillus ferrooxidans. Sep. Purif. Technol. 147, 210-219 (2015)

4. $\quad$ Chen, Y., Chen, M., Li, Y., Wang, B., Chen, S., Xu, Z.: Impact of technological innovation and regulation development on e-waste toxicity: A case study of waste mobile phones. Sci. Rep. 8, 19 (2018)

5. Hagelüken, C.: Mining our computers -opportunities and challenges to recover scarce and valuable metals from end-of-life electronic devices. Electron. Goes Green 2008+. 623-628 (2008)

6. Pascual, P., Nadal, J.: El coure: Producció i consum a l'era industrial. (2008)

7. Cui, J., Zhang, L.: Metallurgical recovery of metals from electronic waste: a review. J. Hazard. Mater. 158, 228-256 (2008)

8. Chen, S., Yang, Y., Liu, C., Dong, F., Liu, B.: Column bioleaching copper and its kinetics of waste printed circuit boards (WPCBs) by Acidithiobacillus ferrooxidans. Chemosphere. 141, $162-168(2015)$

9. Dong, Y., Lin, H., Xu, X., Zhou, S.: Bioleaching of different copper sulfides by Acidithiobacillus ferrooxidans and its adsorption on minerals. Hydrometallurgy. 140, 42-47 (2013)

10. Rohwerder, T., Gehrke, T., Kinzler, K., Sand, W.: Bioleaching review part A: progress in bioleaching: fundamentals and mechanisms of bacterial metal sulfide oxidation. Appl. Microbiol. Biotechnol. 63, 239-248 (2003)

11. Olson, G.J., Briyazierley, J.A, Brierley, C.L.: Bioleaching review part B: progress in bioleaching: applications of microbial processes by the minerals industries. Appl. Microbiol. Biotechnol. 63, 249-257 (2003)

12. Dorado, A.D., Solé, M., Lao, C., Alfonso, P., Gamisans, X.: Effect of pH and Fe(III) ions on chalcopyrite bioleaching by an adapted consortium from biogas sweetening. Miner. Eng. 39, 3638 (2012)

13. Qu, Y., Lian, B.: Bioleaching of rare earth and radioactive elements from red mud using Penicillium tricolor RM-10. Bioresour. Technol. 136, 16-23 (2013)

14. Klink, C., Eisen, S., Daus, B., Heim, J., Schlömann, M., Schopf, S.: Investigation of Acidithiobacillus ferrooxidans in pure and mixed-species culture for bioleaching of Theisen sludge from former copper smelting. J. Appl. Microbiol. 120, 1520-1530 (2016)

15. Mražíková, A., Marcinčáková, R., Kaduková, J., Velgosová, O.: Influence of bacterial culture to copper bioleaching from printed circuit boards. Inz. Miner. 14, 59-62 (2013) 
16. Willner, J., Fornalczyk, A.: Extraction of metals from electronic waste by bacterial leaching. Environ. Prot. Eng. 39, 197-208 (2013)

17. Choi, M.S., Cho, K.S., Kim, D.S., Kim, D.J.: Microbial recovery of copper from printed circuit boards of waste computer by Acidithiobacillus ferrooxidans. J. Environ. Sci. Health. A. Tox. Hazard. Subst. Environ. Eng. 39, 2973-2982 (2004)

18. Liang, G., Tang, J., Liu, W., Zhou, Q.: Optimizing mixed culture of two acidophiles to improve copper recovery from printed circuit boards (PCBs). J. Hazard. Mater. 250-251, 238-245 (2013)

19. Bas, A.D., Deveci, H., Yazici, E.Y.: Bioleaching of copper from low grade scrap TV circuit boards using mesophilic bacteria. Hydrometallurgy. 138, 65-70 (2013)

20. Ilyas, S., Anwar, M.A., Niazi, S.B., Afzal Ghauri, M.: Bioleaching of metals from electronic scrap by moderately thermophilic acidophilic bacteria. Hydrometallurgy. 88, 180-188 (2007)

21. Isildar, A., van de Vossenberg, J., Rene, E.R., van Hullebusch, E.D., Lens, P.N.L.: Two-step bioleaching of copper and gold from discarded printed circuit boards (PCB). Waste Manag. 57, 149-157 (2016)

22. Zhu, N., Xiang, Y., Zhang, T., Wu, P., Dang, Z., Li, P., Wu, J.: Bioleaching of metal concentrates of waste printed circuit boards by mixed culture of acidophilic bacteria. J. Hazard. Mater. 192, 614-619 (2011)

23. Xia, M.C., Wang, Y.P., Peng, T.J., Shen, L., Yu, R.L., Liu, Y.D., Chen, M., Li, J.K., Wu, X.L., Zeng, W.M.: Recycling of metals from pretreated waste printed circuit boards effectively in stirred tank reactor by a moderately thermophilic culture. J. Biosci. Bioeng. 123, 714-721 (2017)

24. Brandl, H., Bosshard, R., Wegmann, M.: Computer-munching microbes: metal leaching from electronic scrap by bacteria and fungi. Hydrometallurgy. 59, 319-326 (2001)

25. Hubau, A., Minier, M., Chagnes, A., Joulian, C., Silvente, C., Guezennec, A.G.: Recovery of metals in a double-stage continuous bioreactor for acidic bioleaching of printed circuit boards (PCBs). Sep. Purif. Technol. 238, (2020)

26. Millero, F.: Speciation of metals in natural waters. Geochem. Trans. 2, 56-64 (2001)

27. Hogle, S.L., Barbeau, K.A., Gledhill, M.: Heme in the marine environment: From cells to the iron cycle. Metallomics. 6, 1107-1120 (2014)

28. Shah, M.B., Tipre, D.R., Purohit, M.S., Dave, S.R.: Development of two-step process for enhanced biorecovery of $\mathrm{Cu}-\mathrm{Zn}-\mathrm{Ni}$ from computer printed circuit boards. J. Biosci. Bioeng. 120, 167-173 (2015)

29. Yang, Y., Chen, S., Li, S., Chen, M., Chen, H., Liu, B.: Bioleaching waste printed circuit boards by Acidithiobacillus ferrooxidans and its kinetics aspect. J. Biotechnol. 173, 24-30 (2014)

30. Shah, M.B., Tipre, D.R., Dave, S.R.: Chemical and biological processes for multi-metal extraction from waste printed circuit boards of computers and mobile phones. Waste Manag. Res. 32, 1134-1141 (2014)

31. Zhang, C., Cai, Y., Wang, J., Bai, J., Zhou, Y., Wu, W., Mao, W.: Recovery of copper from bioleaching solutions of waste printed circuit boards waste by ion exchange. In: Proceedings - 2010 International Conference on Digital Manufacturing and Automation, ICDMA 2010 (2010)

32. Khattab, I.A., Shaffei, M.F., Shaaban, N.A., Hussein, H.S., Abd El-Rehim, S.S.: Electrochemical removal of copper ions from dilute solutions using packed bed electrode. Part II. Egypt. J. Pet. 22, 205-210 (2013)

33. Agrawal, R., Kapoor, M.: Theoretical considerations of the cementation of copper with iron. JS Afr. Inst. Min. Met. 106-111 (1982)

34. Jhajharia, R., Jain, D., Sengar, A., Goyal, A., Soni, P.R.: Synthesis of copper powder by mechanically activated cementation. Powder Technol. 301, 10-15 (2016)

35. Rossi, G., Trois, P., Visca, P.: In-situ pilot semi-commercial bioleaching test at the San Valentino 
di Predoi mine (Northern Italy). In: Fundamental and Applied Biohydrometallurgy: Proceedings of the Sixth International Symposium on Biohydrometallurgy. pp. 173-189 (1986)

36. Agate, A.D., Khinvasara, N.J.: Bioleaching of copper ores and concentrate of malankhand area, India. Biotechnol. Bioeng. Symp. 16, 83-90 (1986)

37. Dib, A., Makhloufi, L.: Cementation treatment of copper in wastewater: Mass transfer in a fixed bed of iron spheres. Chem. Eng. Process. Process Intensif. 43, 1265-1273 (2004)

38. Jeffery, G.H., Bassett, J., Mendham, J., Denney, R.C.: Vogel's textbook of quantitative chemical analysis. Longman Scientific \& Technical, England (1989)

39. Barron, J.L., Luecking, D.R.: Growth and maintenance of Thiobacillus ferrooxidans cells. Appl. Environ. Microbiol. 56, 2801-2806 (1990)

40. Veit, H.M., de Pereira, C.C., Bernardes, A.M.: Using mechanical processing in recycling printed wiring boards. Jom. 54, 45-47 (2002)

41. Ayres, R.U.: Metals recycling: Economic and environmental implications. Resour. Conserv. Recycl. 21, 145-173 (1997)

42. Bizzo, W.A., Figueiredo, R.A., De Andrade, V.F.: Characterization of printed circuit boards for metal and energy recovery after milling and mechanical separation. Materials (Basel). 7, 45554566 (2014)

43. Kobe, K.A., Dickey, W.: Oxidation of ferrous sulfate solutions with oxygen. Ind. Eng. Chem. 37, 429-431 (1945)

44. Yazici, E.Y., Deveci, H.: Ferric sulphate leaching of metals from waste printed circuit boards. Int. J. Miner. Process. 133, 39-45 (2014)

45. Xiang, Y., Wu, P., Zhu, N., Zhang, T., Liu, W., Wu, J., Li, P.: Bioleaching of copper from waste printed circuit boards by bacterial consortium enriched from acid mine drainage. J. Hazard. Mater. 184, 812-8 (2010)

46. Hubau, A., Minier, M., Chagnes, A., Joulian, C., Perez, C., Guezennec, A.G.: Continuous production of a biogenic ferric iron lixiviant for the bioleaching of printed circuit boards (PCBs). Hydrometallurgy. 180, 180-191 (2018)

47. Kaksonen, A.H., Morris, C., Rea, S., Li, J., Wylie, J., Usher, K.M., Ginige, M.P., Cheng, K.Y., Hilario, F., Du Plessis, C.A.: Biohydrometallurgical iron oxidation and precipitation: Part i Effect of $\mathrm{pH}$ on process performance. Hydrometallurgy. 147-148, 255-263 (2014)

48. Torres, R., Lapidus, G.T.: Copper leaching from electronic waste for the improvement of gold recycling. Waste Manag. 57, 131-139 (2015)

49. Anastassakis, G.N., Bevilacqua, P., De Lorenzi, L.: Recovery of residual copper from lowcontent tailings derived from waste electrical cable treatment. Int. J. Miner. Process. 143, 105$111(2015)$

50. Alers, G.B., Lu, X., Sukamto, J.H., Reid, J., Harm, G.: Influence of copper purity on microstructure and electromigration. Proc. IEEE 2004 Int. Interconnect Technol. Conf. 45-47 (2004)

51. Sinha, R., Chauhan, G., Singh, A., Kumar, A., Acharya, S.: A novel eco-friendly hybrid approach for recovery and reuse of copper from electronic waste. J. Environ. Chem. Eng. 6, 1053-1061 (2018)

52. David, D.J., Pradhan, D., Das, T.: Evaluation of iron oxidation rate of Acidithiobacillus ferrooxidans in presence of heavy metal ions. Miner. Process. Extr. Metall. 117, 56-61 (2008)

53. Cho, K.S., Ryu, H.W., Choi, H.M.: Toxicity Evaluation of Complex Metal Mixtures Using Reduced Metal Concentrations: Application to Iron Oxidation by Acidithiobacillus ferrooxidans. J. Microbiol. Biotechnol. 18, 1298-1307 (2008) 
1

$$
2
$$$$
3
$$$$
\begin{aligned}
& 4 \\
& 5 \\
& 6
\end{aligned}
$$ 